\title{
SISTEM PERINGATAN DINI BANJIR SUNGAI BENGAWAN SOLO MENGGUNAKAN TEKNOLOGI INTERNET OF THINGS (IOT)
}

\author{
Nanang Maulana Y \\ Fakultas MIPA, Program Studi D3 Teknik Informatika \\ Universitas Sebelas Maret \\ Email: nanang.my@staff.uns.ac.id \\ Arif Purwo Nugroho, Andri Adi Nugroho, Agung Eko Saputro \\ Fakultas MIPA, Program Studi D3 Teknik Informatika \\ Universitas Sebelas Maret
}

\section{Info Artikel}

Kata Kunci :

Internet of Things (loT), Arduino

UNO, Peringatan Dini Banjir, Sungai

Bengawan Solo

Keywords :

Internet of Things, Arduino UNO, mitigation, Bengawan Solo river

\section{Abstrak}

Bencana banjir merupakan bencana alam yang banyak menyebabkan kerugian, baik jiwa maupun meteriil. Sungai Bengawan Solo merupakan salah satu sungai yang setiap tahun mengalami bencana banjir. Untuk meningkatkan kesiapsiagaan terhadap datangnya banjir di sungai Bengawan Solo, dibuatlah sebuah sistem peringatan dini banjir dengan menggunakan teknologi Internet of Things (IOT). Sistem ini terdiri dari alat pendeteksi ketinggian air, menggunakan sensor ultrasonic dan arduino uno, dan server IoT. Informasi mengenai ketinggian air sungai bengawan solo dapat diakses oleh pengguna melalui website dan android. Pengguna akan mendapatkan infromasi ketinggian air sungai secara real time. Level peringatan dapat diatur secara independen untuk tiap-tiap pengguna. Peringatan banjir dikirimkan menggunakan sms dan pesan notifikasi untuk versi android.

\section{Abstarct}

Flood disaster is a natural disaster that causes many losses, both soul and meteriil. Bengawan Solo River is one of the rivers that every year experiencing flood disaster. To improve preparedness for flooding in solo bengawan river, a flood early warning system was created using the Internet of Things (IoT) technology. This system consists of a water level detector, using ultrasonic sensors and arduino uno, and iot servers. Information about the water level of the bengawan solo river can be accessed by users through the website and android. Users will get river water level infromation in real time. Warning level can be set independet for each user. Flood warnings are sent using sms and notification messages for android versions. 


\section{PENDAHULUAN}

Internet of Things (IOT) merupakan enabler yang menghubungkan device-device dan melakukan pertukaran pesan diantara device tersebut. Device-device yang dihubungkan bisa berupa sensor, appliances, embedded system, dan data analysis microchip. IoT sangat bermanfaat dalam bidang environmental monitoring, khususnya untuk Early Warning System atau Sistem Peringatan Dini dan analisa data lingkungan [1].

Pada kasus bencana banjir, sebuah sistem peringatan ketinggian air sangat berperan penting untuk memberikan peringatan dini kepada masyarakat di sekitar daerah terdampak sehingga mampu melakukan tindakan seperti evakuasi, dan sebagainya. Sistem peringatan dini menjadi bagian penting dari mekanisme kesiapsiagaan masyarakat, karena peringatan dini dapat menjadi faktor kunci yang menghubungkan antara tahap kesiapsiagaan dan tanggap darurat. Apabila peringatan dini disampaikan tepat waktu, maka suatu peristiwa yang dapat menimbulkan bencana dapat diperkecil dampak negatifnya [2].

Daerah Aliran Sungai (DAS) Bengawan Solo merupakan DAS yang sering terjadi banjir. Curah hujan yang tinggi pada musim penghujan mengakibatkan DAS ini tidak mampu menampung aliran langsung permukaan yang masuk ke sistem sungai sehingga terjadi luapan yang menggenangi di sekitar wilayah-wilayah yang dilalui oleh sungai utamanya. Selain banjir yang mengancam sejumlah wilayah di hulu sungai, seperti Solo dan Sragen, banjir juga mengancam sejumlah wilayah hilir, yaitu Bojonegoro, Lamongan, Tuban dan Gresik di Provinsi Jawa Timur [3].

Pembuatan Sistem Peringatan Dini bencana banjir, khususnya di Sungai Bengawan Solo, sangat diperlukan untuk menguatkan individu dan masyarakat yang terancam bencana untuk bertindak secara tepat, efektif dan benar sehingga dapat mengurangi terjadinya kerusakan fisik dan kematian. Pemanfaatan loT memungkinkan diperolehnya data-data mengenai kondisi alam yang menjadi indikasi akan adanya bencana banjir. Data-data tersebut bisa digunakan menjadi tolok ukur bagi masyarakat untuk bertindak secar tepat untk mengurangi kemungkinan terjadinya korban, hilangnya jiwa, serta kerusakan fisik dan lingkungan.

\section{METODOLOGI PENELITIAN}

Sistem peringatan dini banjir yang dibahas dalam paper ini terdiri dari sensor ultrasonic HC-SRO4 [4], yang berfungsi mendeteksi ketinggian muka air sungai. Arduino UNO sebagai kontroller, yang membaca data ketinggian air sungai dan mengirimkannnya ke server menggunakan GSM-GPRS Arduino shield dengan chip SIM900A yang mengatur transmisi data. Pengiriman data dari sensor ke server menggunakan jalur komunikasi data menggunakan layanan GRPS/3G. Server kemudian mengolah data ketinggian air untuk ditampilkan melalui website. Apabila ketinggian air telah melampaui batas yang ditentukan, maka server akan mengirimkan peringatan melalui SMS dan notifikasi Android. Arsitektur sistem peringatan dini banjir dapat dilihat pada Gambar 1.

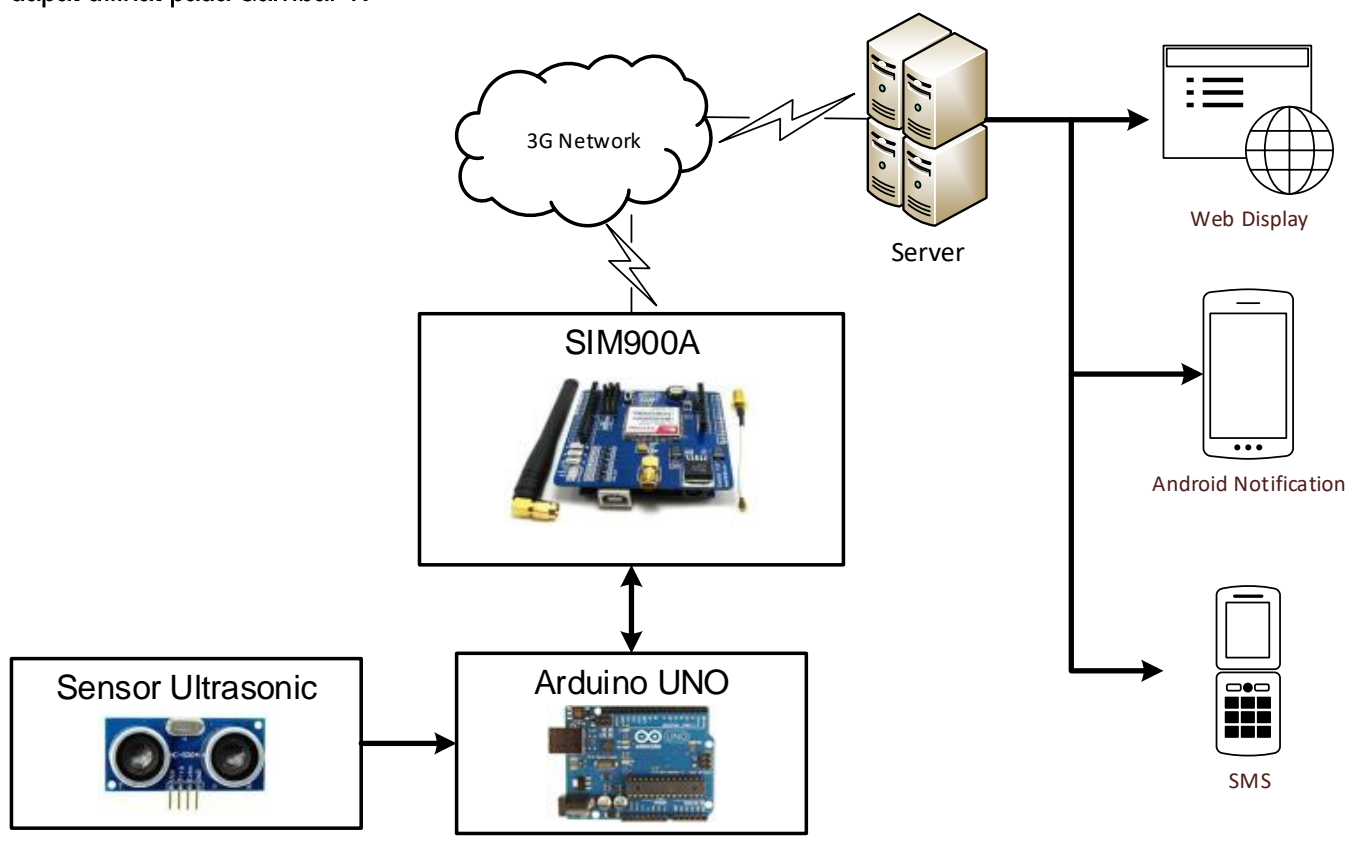

Gambar 1. Arsitektur Sistem Peringatan Dini Banjir 
Ketinggian level air sungai diukur menggunakan sensor ultrasonic HC-SR04. Gelombang ultrasonic dengan frekuensi 40 $\mathrm{KHz}$ dipancarkan oleh transmitter, kemudian receiver menangkap hasil pantulan gelombang ultrasonic setelah mengenai suatu object. Tampilan sensor ultrasonic HC-SR04 ditunjukkan oleh Gambar 2. Arduino UNO akan menghitung perbedaan waktu antara gelombang yang dikirimkan oleh transmitter dan gelombang pantulan yang diterima oleh receiver. Kecepatan suara (V) pada suhu $(T) 0^{\circ} \mathrm{C}$ berkisar $331.5 \mathrm{~m} / \mathrm{s}$, yang meningkat $0.6 \mathrm{~m} / \mathrm{s}$ setiap kenaikan $1^{\circ} \mathrm{C}$. Kecepatan suara dan jarak $(D)$ antara object dan sensor pada waktu $t$ dihitung berdasarkan persamaan (1) dan (2) [5].

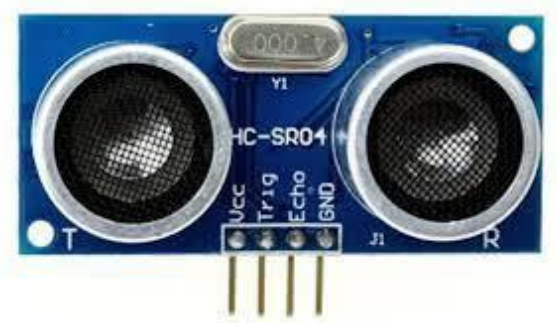

Gambar 2. Ultrasonic HC-SRO4 Module

$$
\begin{aligned}
& v_{\text {udara }}=331.5+(0.6 \times T) \\
& D=\frac{v \times y}{2}
\end{aligned}
$$

Arduino merupakan sebuah open-source prototyping platform yang mendasarkan pada kemudahan penggunaan hardware dan sofware[6]. Dalam penelitian ini, board Arduino yang digunakan adalah Arduino UNO. Arduino UNO merupakan board mikrokontroller berbasis chip ATMega328. Arduino UNO mempunyai 14 digital I/O pin, 6 input analog, 16 Mhz quartz crystal, USB connector, ICSP header dan tombol reset. UNO menggunakan programmed ATMega16U2 sebagai USB ke Serial converter [7]. Tampilan Arduino Uno ditunjukkan oleh Gambar 3.

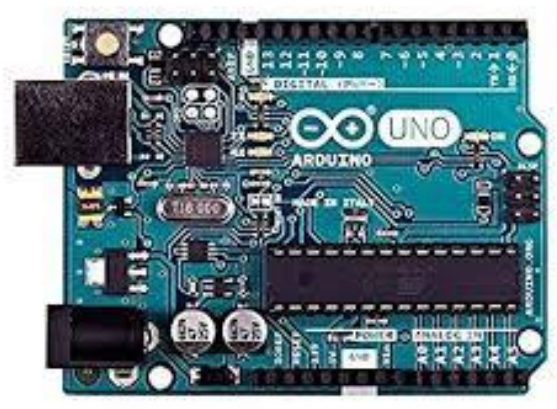

\section{Gambar 3. Arduino UNO}

SIM900 GSM/GPRS Shield merupakan GSM/GPRS shield kompatibel dengan arduino yang menggunakan SIM900 Quad-band GSM/GPRS module. Module ini dikotrol menggunakan AT command (GSM 07.07, 07.05 san SIMCOM enhanced AT Command)[7]. GSM/GPRS shield terhubung ke Arduino UNO dan berfungsi untuk mengirimkan data ketinggian air ke server menggunakan jaringan GPRS. Tampilan SIM 900A GSM/GPRS Shield bisa dilihat pada Gambar 4. 


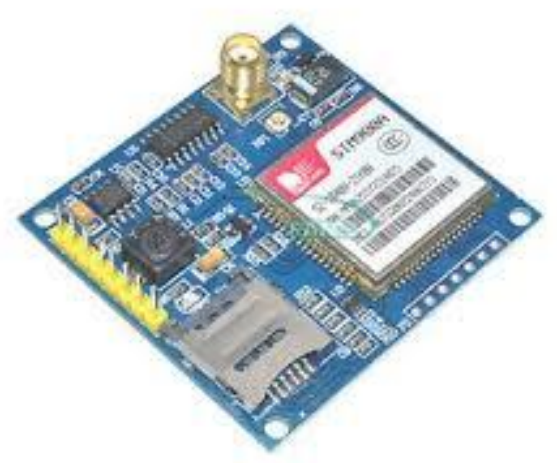

Gambar 4. SIM900A GSM/GPRS Shield [8]

Perancangan website sistem, yang berfungsi sebagai penyimpan data yang dikirimkan oleh sensor dan menampilkannya ke masyarakat, berturut-turut dilakukan dengan melakukan perancangan fungsional, perancangan database dan perancangan antarmuka sistem. Untuk perancangan fungsional, digunakan diagram Use case untuk menggambarkan fungsi-fungsi yang bisa dilakukan oleh masisng-masing aktor di dalam sistem. Use case diagram dari sistem ditunjukkan oleh Gambar 5.

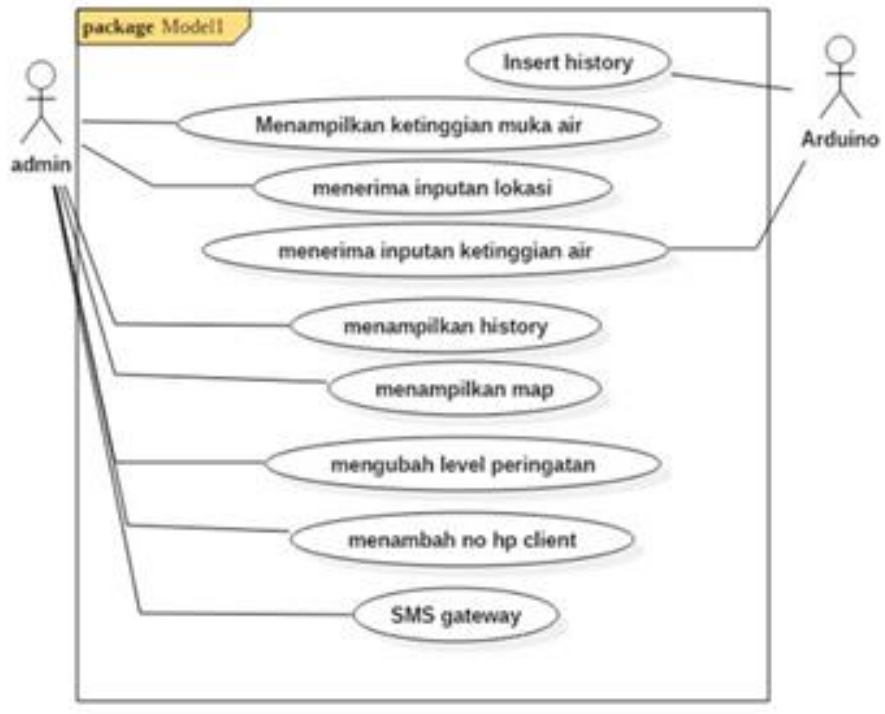

\section{Gambar 5. Use Case Sistem Peringatan Dini Banjir}

Perancangan database berfungsi untuk menggambarkan database yang akan digunakan untuk menyimpan data-data yang diperlukan. Penggambaran rancangan database ditunjukkan oleh Entity Relationship Diagram (ERD) sistem. ERD dari sistem peringatan dini banjir dapat dilihat pada Gambar 6. Entitas yang terlibat di dalam sistem adalah Admin dan user. Entitas user merupakan masyarakat yang akan mendapat peringatan berupa Short Message Service (SMS) apabila ketinggian air sungai mencapai titik tertentu. 


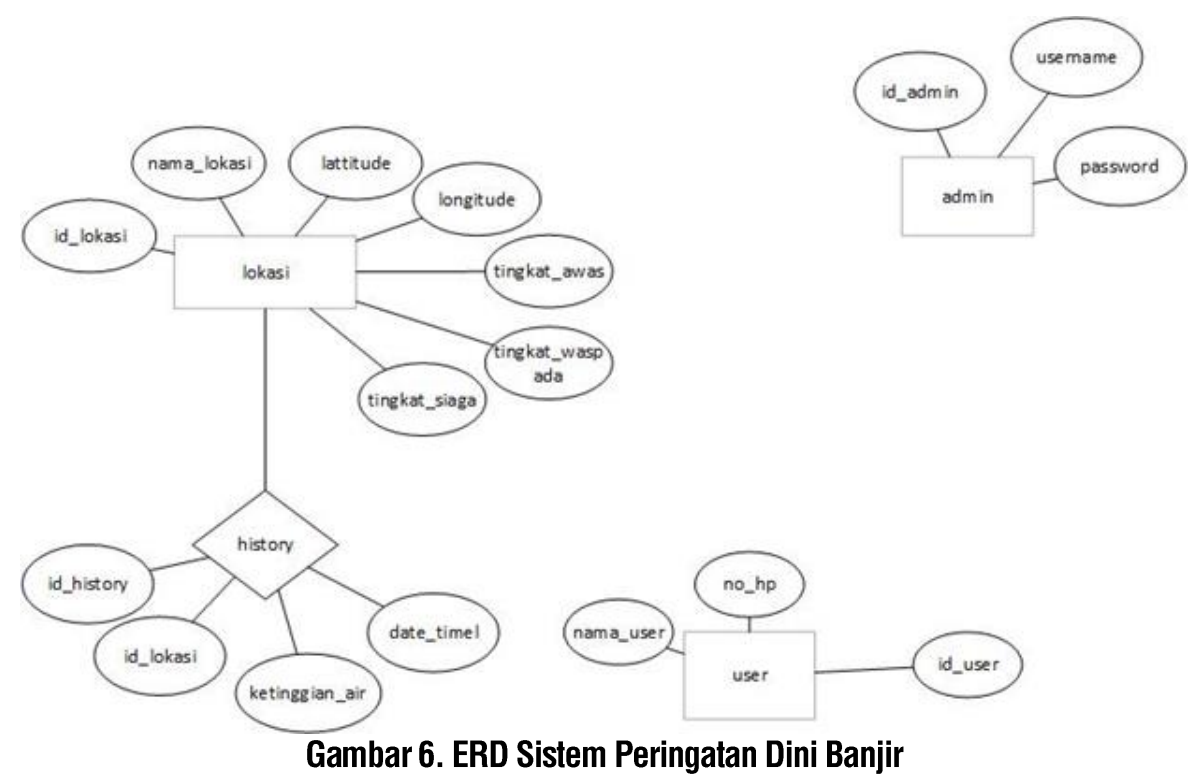

Perancangan antarmuka sistem terdiri dari perancangan antarmuka untuk Admin dan antarmuka yang bisa diakses oleh masyarakat. Perancangan antarmuka untuk Admin ditunjukkan oleh Gambar 7(a), sedangkan perancangan antarmuka untuk tampilan yang bisa diakses oleh masyarakat ditunjukkan pada Gambar 7(b).

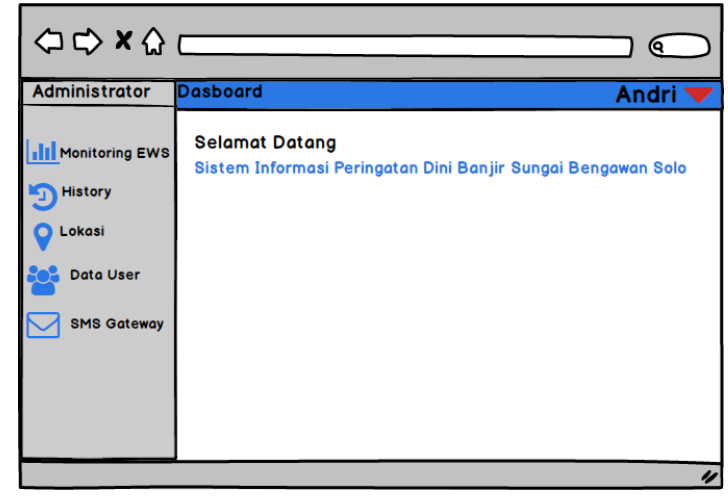

(a)

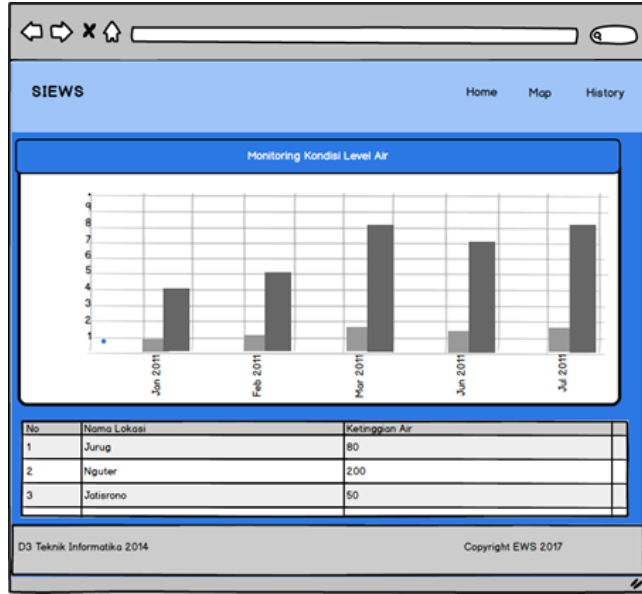

(b)

Gambar 7(a). Perancangan Antarmuka untuk Admin. (b) Perancangan Antarmuka Untuk tampilan umum.

Selain antarmuka dalam bentuk website, sistem peringatan dini banjir juga bisa diakses menggunakan perangkat android. Perancangan antarmuka untuk aplikasi android ditunjukkan oleh Gambar 8. 


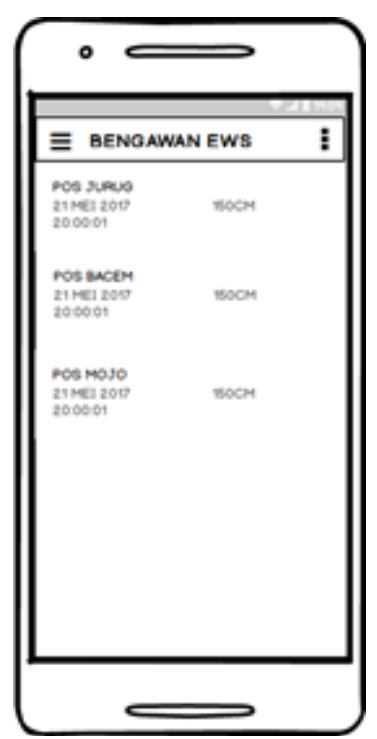

Gambar 8. Perancangan antarmuka untuk Android

\section{HASIL DAN PEMBAHASAN}

Sebelum dipasang di lapangan, sistem peringatan dini banjir diuji di dalam laboratorium. Pengujian laboratorium menggunakan pipa yang diberi penghalang berupa sekat geser untuk mensimulasikan ketinggian air. Data dibaca oleh sensor dan dikirimkan ke server setiap 5 menit. Jarak divariasi antara 200 sampai $400 \mathrm{~cm}$, dengan step setiap $20 \mathrm{~cm}$. Sensor ultrasonic HC-SRO4 yang ditempatkan di dalam pipa tidak berpengaruh pada pembacaan sensor, atau dengan kata lain sensor HC-SR04 masih bisa berfungsi dengan baik walaupun ditempatkan pada pipa PVC[9]. Model pengujian sistem sensor peringatan dini banjir ditunjukkan oleh Gambar 9.

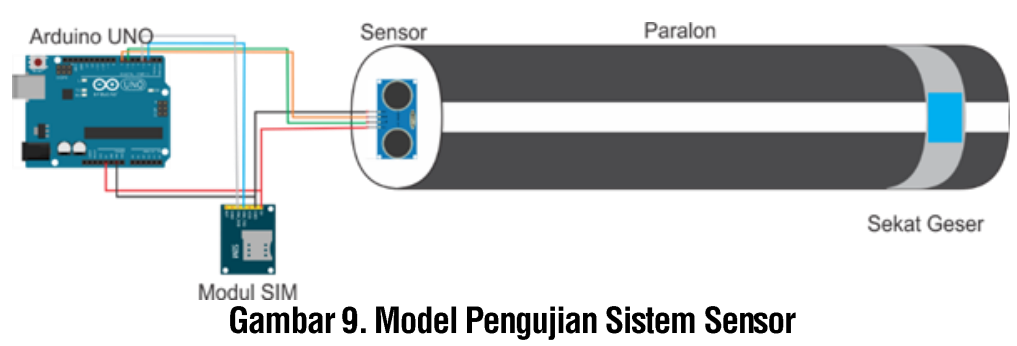

Hasil pengujian menggunakan sensor ultrasonic HC-SR04 yang digunakan untuk mengukur jarak antara sensor dengan penghalang ditunjukkan oleh Gambar 10. Grafik pada Gambar 10 menunjukkan pembacaan sensor ultrasonic HC-SR04 ketika penghalang digeser. Dari grafik tersebut menunjukkan bahwa sensor ultrasonic cukup akurat untuk digunakan membaca ketinggian permukaan air, dengan nilai $\mathrm{R}^{2}$ adalah 0,99 . 


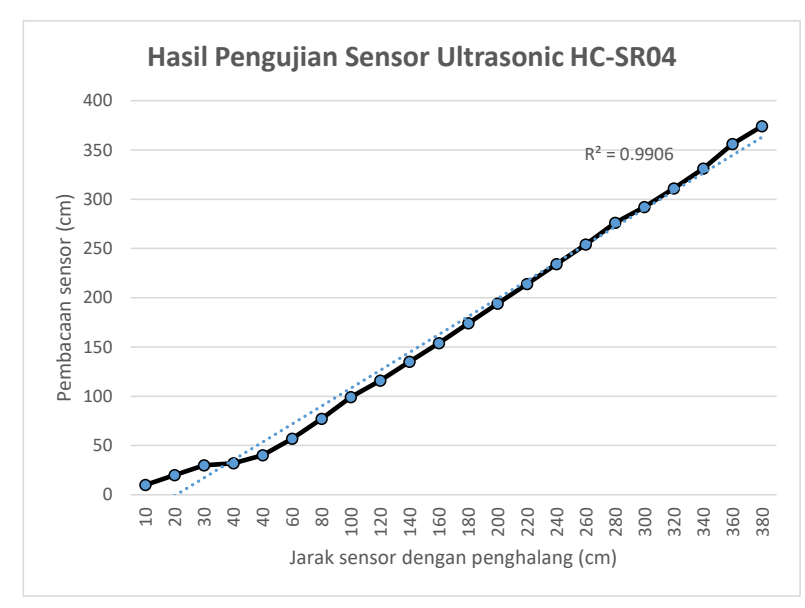

\section{Gambar 10. Hasil Pengujian Sensor Ultrasonic}

Implementasi untuk antarmuka yang bisa dikases oleh masyarakat ditunjukkan oleh Gambar 11. Dalam antarmuka tersebut ditunjukkan ketinggian air pada lokasi-lokasi dimana sensor ketinggian air dipasang beserta nilai ketinggian air pada lokasi tersebut. Informasi ketinggian air selain ditampilkan dalam bentuk grafik, juga ditampilkan dalam bentuk tabel.

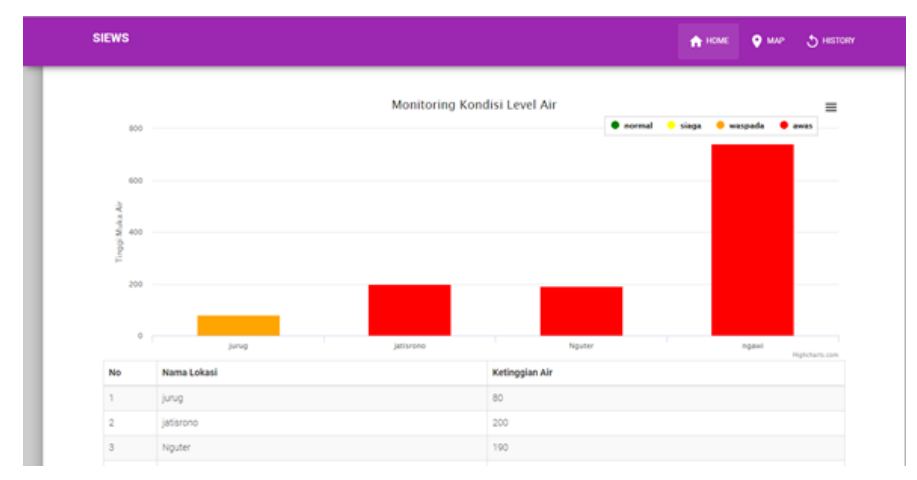

\section{Gambar 11. Antarmuka Sistem Peringatan Dini Banjir}

Implementasi antarmuka untuk Android ditunjukkan oleh Gambar 12(a) dan 12(b). Pada antarmuka Android, ditampilkan informasi lokasi sensor ketinggian, tanggal data terakhir, dan ketinggian muka air yang dibaca oleh sensor.

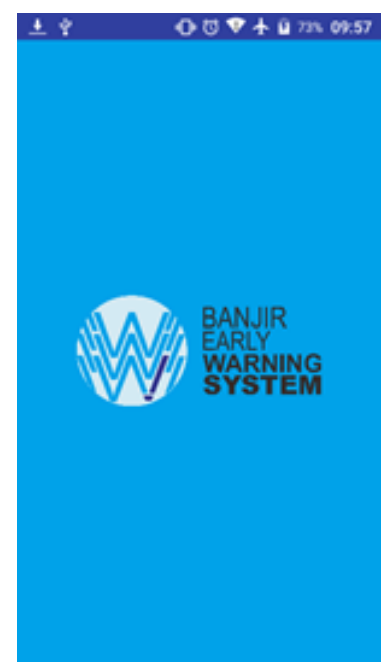

(a)

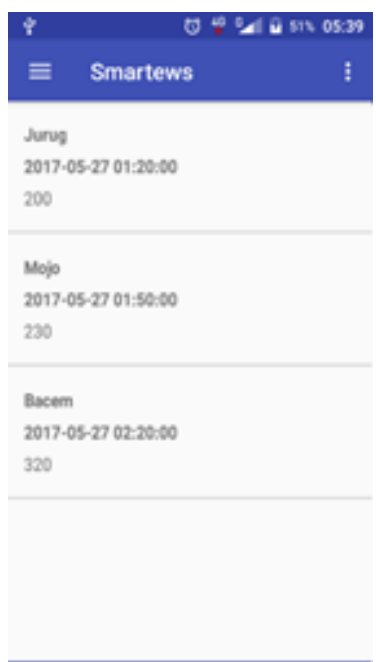

(b)

Gambar 12(a). Splash Screen untuk Antarmuka Android. (b) Antarmuka Sistem Peringatan Dini Pengguna versi Android 


\section{KESIMPULAN}

Hasil dari penelitian ini adalah telah dirancang dan dibuat Sistem Peringatan Dini Banjir yang telah dipasang di sungai Bengawan Solo dan dapat memberikan informasi ketinggian muka air sungai. Antarmuka sistem berupa website dan aplikasi Andriod. Sistem dapat memberikan peringatan ketika ketinggian air sungai mencapai titik tertentu. Peringatan berupa berubahnya warna tampilan website, SMS dan notifikasi pada perangkat Android.

\section{DAFTAR PUSTAKA}

[1] T. Perumal, N. Sulaiman, and C. Y. Leong, "Internet of Things ( IoT ) Enabled Water Monitoring System," 2015 IEEE 4th Glob. Conf. Consum. Electron. Internet, pp. 86-87, 2015.

[2] Anonim, "Pedoman Sistem Peringatan Dini Berbasis Masyarakat," no. September, 2012.

[3] P. D. Raharjo, "Integrasi Data Penginderaan Jauh Citra Landsat TM Dan SRTM Untuk Deteksi Rawan Banjir Di DAS Bengawan Solo," pp. 4-7.

[4] Indoware, "Ultrasonic Ranging Module HC - SR04," Datasheet, pp. 1-4, 2013.

[5] 0. Intharasombat and P. Khoenkaw, "A low-cost flash flood monitoring system," Proc. - 2015 7th Int. Conf. Inf. Technol. Electr. Eng. Envisioning Trend Comput. Inf. Eng. ICITEE 2015, pp. 476-479, 2016.

[6] M. A. Wister, J. A. Hernandez-Nolasco, P. Pancardo, F. D. Acosta, and A. Jara, "Emergency population warning about floods by social media," Proc. - 2016 10th Int. Conf. Innov. Mob. Internet Serv. Ubiquitous Comput. IMIS 2016, pp. 322-327, 2016.

[7] I. A. Zakarya, F. Naemah, M. Saad, M. Zaim, and M. Nor, "DEVELOPMENT OF PORTABLE WATER LEVEL SENSOR FOR FLOOD MANAGEMENT SYSTEM," vol. 11, no. 8, pp. 5352-5357, 2016.

[8] Anonim, "User Manual GPRS/GSM SIM900a Modem With Arduino Compatible." www.researchdesignlab.com.

[9] E. Kuantama, L. Setyawan, and J. Darma, "Early flood alerts using Short Message Service (SMS)," Proc. 2012 Int. Conf. Syst. Eng. Technol. ICSET 2012, pp. 3-7, 2012. 